\title{
Evaluating the status of the Endangered tiger Panthera tigris and its prey in Panna Tiger Reserve, Madhya Pradesh, India
}

\author{
Rajesh Gopal, Qamar Qureshi, Manish Bhardwa \\ R.K. JAGA Dis H S INGH and YADVENDRADEV V. JHALA
}

\begin{abstract}
We evaluated the status of tigers Panthera tigris and their prey in Panna Tiger Reserve using occupancy surveys, camera-trap mark-recapture population estimation, and distance sampling along foot transects, in 2006. Forest Range tiger occupancy in the Panna landscape $\left(3,500 \mathrm{~km}^{2}\right)$ estimated by 1,077 surveys of $5 \mathrm{~km}$ each was $29 \% \pm$ SE 1 . Within occupied Ranges of the Reserve a mean of $68 \% \pm$ SE 7 of forest Beats had tiger signs. A total of 800 camera-trap nights yielded 24 captures of seven individual adult tigers within an effective trap area of $185.0 \pm$ SE $15.8 \mathrm{~km}^{-2}$. The best model incorporating individual heterogeneity $\left(M_{h}\right)$ estimated the tiger population to be $9 \pm$ SE 2 . Tiger density was $4.9 \pm$ SE 1.5 per $100 \mathrm{~km}^{2}$ and was lower than that reported in 2002 (6.49 tigers per $100 \mathrm{~km}^{2}$ ). Both occupancy and density indicated a decline of the tiger population in the Reserve. Mean ungulate density was $42.4 \pm$ SE $8.4 \mathrm{~km}^{-2}$ and comparable to other tiger reserves. Since our survey in 2006 tiger status in Panna has deteriorated further because of poaching. Panna was occupied by dacoits in late 2006 and anti-insurgent activities caused further disturbances. In late 2008 there was a single male tiger left in Panna but he has not been seen since January 2009. The Madhya Pradesh Forest department has reintroduced three tigers to Panna from neighbouring tiger reserves. Panna, along with Sariska Tiger Reserve, exemplifies the vulnerability of small, isolated tiger populations to local extinctions caused by poaching, even in areas with suitable habitat and sufficient prey.
\end{abstract}

Keywords India, local extinction, mark-recapture, occupancy, Panna Tiger Reserve, Panthera tigris, tiger, ungulates

\section{Introduction}

7 iger Panthera tigris numbers and range continue to 1 decline despite national and international efforts to conserve the species (Chundawat et al., 2008). Habitat loss,

Rajesh Gopal National Tiger Conservation Authority, Bikaner House, New Delhi, India

QAmar Qureshi, Manish BhardwaJ, R.K. Jagadish Singh and YADVENDRADEV V. JHALA (Corresponding author) Wildlife Institute of India, Post Box \#18, Dehradun 248001, Uttarakhand, India. E-mail jhalay@wii.gov.in

Received 3 March 2009. Revision requested 5 May 2009.

Accepted 22 October 2009. fragmentation, prey depletion and poaching are considered the major factors responsible for this decline (Dinerstein et al., 2007). However, it is unclear which of these factors is of primary importance in causing local extirpations of tigers (Kenney et al., 1995; Karanth \& Stith, 1999; Sunquist et al., 1999; Karanth et al., 2004b, 2006; Chapron et al., 2008). A major limitation in designing and implementing site-specific conservation measures is the lack of reliable methods for assessing and monitoring the status of tigers over landscapes (Karanth et al., 2003; but see Linkie et al., 2006).

Official reports on the status of tigers in India's tiger reserves lost credibility following the local extinction of tigers in Sariska Tiger Reserve. Census figures continued to report substantial numbers in the Reserve even when there were none left (Narain et al., 2005). The Tiger Task Force, appointed by the Prime Minister, recommended using occupancy (Mackenzie et al., 2003) and capture-recapture with camera traps (Karanth \& Nichols, 2002), as proposed by Jhala et al. (2005a,b), to evaluate tiger status. There is also controversy regarding the status of tigers in Panna Tiger Reserve (Sinha, 2007; Chundawat \& Van Gruisen, 2008; Pabla, 2008). Both Sariska and Panna Tiger Reserves share several characteristics: harbouring small, isolated tiger populations, with reasonably good prey populations and habitat but surrounded by non-sympathetic local communities.

Here we report the results of a stepwise approach used to evaluate the status of tigers in Panna Tiger Reserve in 2006. We first estimate occupancy (Mackenzie et al., 2003) using sign surveys across the forested landscape of which Panna Tiger Reserve is a part, and subsequently estimate population size by camera-trap capture-recapture (Pollock et al., 1990; Karanth \& Nichols, 2002) in the area containing the highest density of tiger signs. We also provide an account of the possible causes of the extinction of tigers in Panna Tiger Reserve.

\section{Study area}

The $542.7 \mathrm{~km}^{2}$ Panna Tiger Reserve in the state of Madhya Pradesh is part of a landscape that consists of an isolated forest patch of 3,500 $\mathrm{km}^{2}$ in the Vindhya hill range (Fig. 1; Qureshi et al., 2006; Jhala et al., 2008). The Reserve ranges in altitude over $330-540 \mathrm{~m}$ and has an average annual 


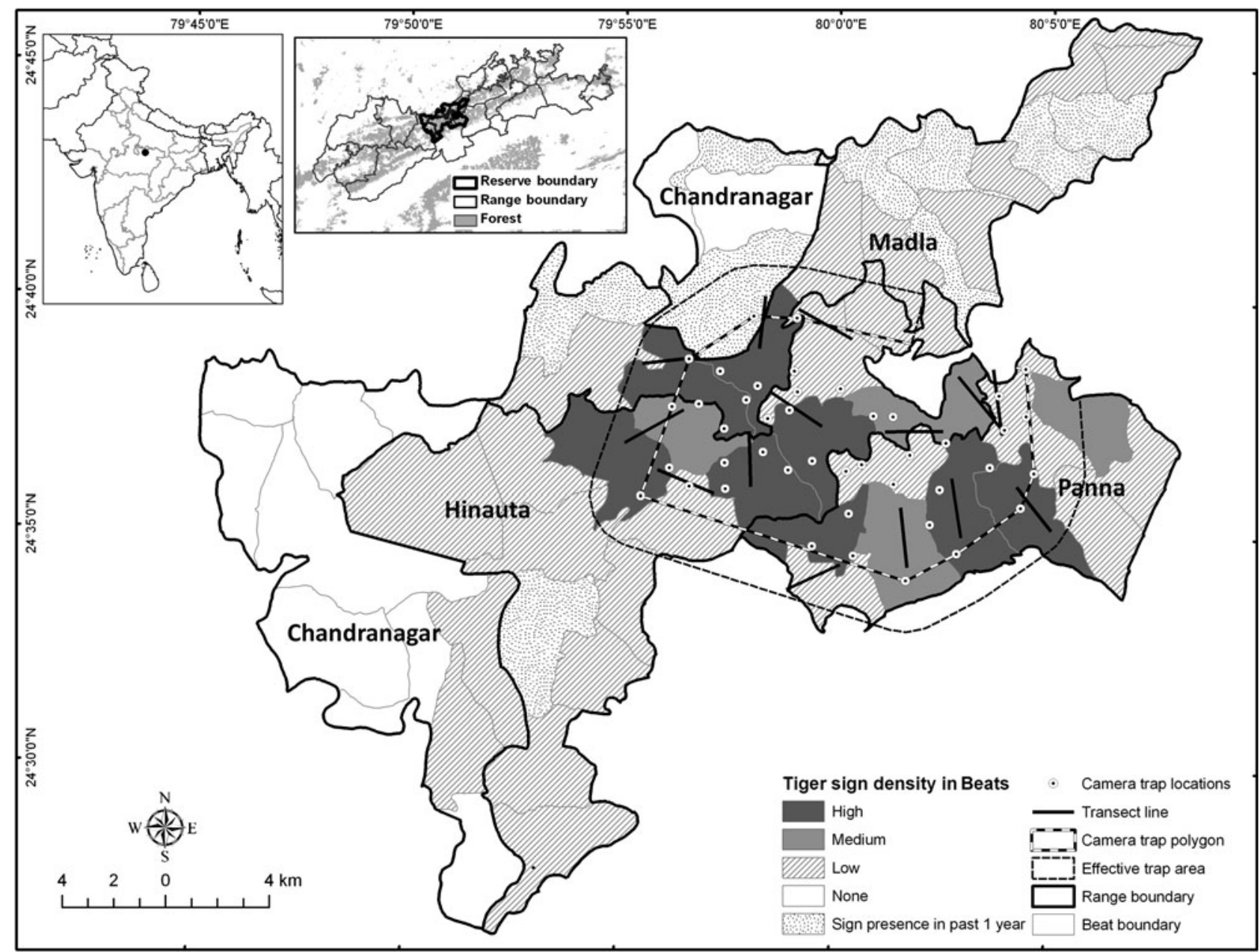

FIg. 1 Beat and Range map of Panna Tiger Reserve showing intensity of tiger Panthera tigris sign, camera locations, effective trap area and placement of transects. The two insets show the location of the forested landscape of Panna ( 21 Ranges, $\left.3,500 \mathrm{~km}^{2}\right)$ in India and the location of Panna Tiger Reserve (4 Ranges) in this landscape.

precipitation of $1,100 \mathrm{~mm}$. The forest of the Reserve is dry deciduous (Champion \& Seth, 1968); teak Tectona grandis and kardhai Anogeissus pendula are the dominant tree species. The Reserve is characterized by plateaus and gorges, which rise from the perennial river Ken that flows for c. 55 $\mathrm{km}$ through the Reserve. The landscape of Panna is fraught with conflict. Traditionally most local and tribal communities depended on hunting as a means of livelihood. Creation of Panna National Park, and its subsequent coverage under Project Tiger, resulted in an alienation of the local communities, the people of which continue to poach wildlife outside, and sometimes inside, the Reserve. Thus, the forest areas outside the Reserve are sinks for both ungulates and carnivores.

\section{Methods}

Most forests in India are divided into a hierarchy of administrative units consisting of Divisions, Ranges, Beats and Compartments. The boundaries of Beats and Compartments are based on natural features such as ridge tops, streams and dirt tracks and are therefore easily recognized in the field. There are 21 Ranges within the forested landscape of Panna and, of these, four form the Panna Tiger Reserve. We searched for tiger signs by walking three $5-\mathrm{km}$ search paths in each Beat across all 21 Ranges of the Panna landscape during January-March 2006. Search paths were in areas where tiger sign was likely to be encountered, such as dirt tracks, dry river beds and forest game paths. Record was kept of all tiger signs (pugmark trails, scats, rake marks, vocalizations and direct sightings). Encounter rates of tiger signs were computed per $\mathrm{km}$ walked (Jhala et al., 2005b). We considered each Range (average size of a Range is $206 \pm \mathrm{SE} 20 \mathrm{~km}^{2}$ ) as the unit for estimating tiger occupancy in the landscape (Mackenzie et al., 2003). Within tiger-occupied Ranges we estimated intensity of use by accounting for detection probability in an occupancy framework by estimating percentage of Beats used by tigers. The software PRESENCE (Hines, 2006) was used for estimating occupancy and detection probability 
of tiger signs. In Ranges where tiger signs were too few for computing detection probabilities we used the average detection probability of tiger sign obtained from all samples for parameter estimation (Mackenzie et al., 2005). Based on tiger signs encountered per $\mathrm{km}$ walked, the Beats were stratified as having high, medium, low and no tiger signs, and were mapped using ArcMap v. 9.2 (ESRI, Redlands, USA).

A contiguous area of $103 \mathrm{~km}^{2}$ with high tiger occupancy, as indicated by signs, was selected for estimating tiger population and density using camera traps (Trailmaster Inc., Lenexa, USA; Karanth \& Nichols, 1998) in Panna Tiger Reserve. A $2 \times 2 \mathrm{~km}$ grid was superimposed on the study area and an intensive ground survey was carried out to find the best location within each grid to deploy a set of camera traps so as to maximize the chances of photographing a tiger. Forty cameras were deployed in pairs over MarchApril 2006 (Fig. 1) to obtain photographs of both flanks of any tigers. The study area was divided into two blocks and cameras moved between blocks at 5-day intervals. A capture matrix was constructed following Karanth et al. (2004a). The first day of camera trapping of each block was combined to constitute the first occasion. Thus, by combining subsequent days of camera trapping we had a total of 20 occasions, with 40 days of sampling, amounting to 800 trap nights. Individual tigers were identified from their unique stripe patterns (Karanth \& Nichols, 1998). An X matrix (Pollock \& Otis, 1983) generated from the capture histories of the photo-captured tigers was analysed in a closed population mark-recapture framework (Chao \& Huggins, 2005). We used software CAPTURE (Rexstad \& Burnham, 1991), which uses a series of goodness of fit tests to compare the null $\left(\mathrm{M}_{\mathrm{o}}\right)$, time effects $\left(\mathrm{M}_{\mathrm{t}}\right)$, behaviour effects $\left(M_{b}\right)$ and individual heterogeneity models $\left(M_{h}\right)$, and combinations of these. It then uses discriminant function analysis for model selection and scores the best fit model with a score close to one. We tested the population closure assumption using software CloseTest (Stanley \& Burnham, 1999).

For computing tiger density the outermost camera locations were joined to form a minimum convex polygon
(Fig. 1). The non-tiger habitats of human settlements and mining activity were removed from this polygon. The effective trapping area was estimated by adding half of the mean maximum distance moved ( $1 / 2 \mathrm{MMDM})$ by recaptured tigers to the minimum convex polygon (Nichols \& Karanth, 2002).

Three replicates of $143-\mathrm{km}$ long line transects were walked between March-April 2006 (Fig. 1) within the camera trap area. For all animal sightings we recorded species, group size, angular distance using a laser range finder and bearing using a sighting compass. Software Distance V (Buckland et al., 2001) was used to compute density of ungulates (chital Axis axis, sambar Cervus unicolor, nilgai Boselaphus tragocamelus, chousingha Tetraceros quadricornis, chinkara Gazella bennettii and wild pig Sus scrofa).

\section{Results}

A total of $5,385 \mathrm{~km}$ were walked in 1,077 surveys covering 359 Beats of 21 Ranges. Six of the Ranges had tiger signs, giving a naïve estimate of $28.6 \%$ Range occupancy. After accounting for detection probability of tiger signs, the biased-corrected Range occupancy obtained using PRESENCE was $29 \% \pm$ SE 1 . The mean detection probability of tiger signs was $0.32 \pm \mathrm{SE}$ 0.03. Within the occupied Ranges of the Reserve 36 of 54 Beats had tiger signs, giving a naïve estimate of Beat usage by tigers of $67 \%$. Bias-corrected mean Beat occupancy obtained with software PRESENCE was $0.68 \pm$ SE 0.07 for the Reserve, with a mean detection probability of $0.74 \pm$ SE 0.05 for tiger signs. Beat occupancy was highest in Hinauta and Panna Ranges (Table 1).

Camera-trapping was carried out in $44 \%$ of the tigeroccupied habitat and the mean effective trapping area of $185 \pm$ SE $15.8 \mathrm{~km}^{2}$ covered all Beats with high tiger signs (Fig. 1). Fifteen photographs of seven individual tigers (four males, two females and one of unidentified gender) were obtained. Software CAPTURE selected model $\mathrm{M}_{\mathrm{h}}$, incorporating individual heterogeneity in capture probabilities, as the best fit, closely followed by the null model $\mathrm{M}_{\mathrm{o}}$ (score 0.96). The average capture probability of tigers was 0.09 for

TABLE 1 Naïve and detection-bias corrected occupancy of forest Beats by tigers Panthera tigris in the four forest Ranges comprising Panna Tiger Reserve (Fig. 1) in 2006.

\begin{tabular}{lllllll}
\hline & No of & No. of search & $\begin{array}{l}\text { Search effort } \\
\text { paths }\end{array}$ & $\begin{array}{l}\text { Naïve } \\
\text { estimate }(\%)\end{array}$ & $\begin{array}{l}\text { Unbiased } \\
\text { occupancy }(\psi) \\
\text { estimate, \% (SE) }\end{array}$ & $\begin{array}{l}\text { Detection } \\
\text { probability (SE) }\end{array}$ \\
\hline Hange $\left(\mathrm{km}^{2}\right)$ & 16 & 48 & 573 & 100 & $100(0.00)$ & $0.75(0.065)$ \\
Panna (96) & 10 & 30 & 357 & 100 & $100(0.00)$ & $0.87(0.06)$ \\
Madla (110) & 14 & 42 & 408 & 62.5 & $65.7(13.02)$ & $0.63(0.10)$ \\
Chandranagar (152) & 14 & 42 & 462 & 14.3 & $14.6^{*}(0.995)$ & $0.05(0.03)$ \\
\hline
\end{tabular}

${ }^{*}$ Detections of tiger signs were too few for estimation of detection probability; therefore the average probability of detecting tiger sign for Panna Tiger Reserve (0.74) was used to compute the occupancy estimate 
model $\mathrm{M}_{\mathrm{h}}$. The overall probability of capturing a tiger within the study area $\left(\mathrm{M}_{\mathrm{t}+1} / \mathrm{N}\right)$ was $77 \%$. Over the trapping duration of 40 days the tiger population was found to be closed $\left(\chi^{2}=14.18, \mathrm{df}=13, \mathrm{P}=0.36\right)$.

Using model $\mathrm{M}_{\mathrm{h}}$ the interpolated mean jackknife population estimate was $9 \pm$ SE 2 tigers (Table 2). The mean maximum distance moved by recaptured tigers was $3.9 \pm \mathrm{SE}$ $0.7 \mathrm{~km}$. The effective trapping area was $185 \pm$ SE $15.8 \mathrm{~km}^{2}$ (Fig. 1). Mean tiger density in the study area was thus estimated to be $4.9 \pm \mathrm{SE} 1.5$ tigers per $100 \mathrm{~km}^{2}$ (Table 2).

Mean wild ungulate density was estimated to be $42.44 \pm$ SE 8.4 individuals $\mathrm{km}^{-2}$ (Table 3 ). The major prey species of tigers (sambar, chital and nilgai) were sighted in numbers sufficient to enable computation of their densities (Table 3) using software DISTANCE.

\section{Discussion}

Occupancy estimates incorporating correction for imperfect detection gave a non-significant increment in area occupied by tigers over the naïve estimate. The bias-corrected estimate of tiger occupancy for Ranges was $0.4 \%$ higher and that for Beats $0.88 \%$ higher than the naïve estimate. Of the six Ranges that had tiger signs, four are within Panna Tiger Reserve. The two Ranges outside the Reserve with tiger signs were Amanganj and Semaria, in both of which tiger signs were recorded in only $1-2$ Beats. Thus, it appears that Panna Tiger Reserve is the source population and the surrounding forested landscape a sink. The Beat occupancy estimates along with their standard errors within tiger occupied Ranges of the Reserve provide a more site-specific parameter for evaluating tiger status as they provide an index of intensity of use that incorporates corrections for imperfect detection. Because this is the first time an occupancy analysis has been carried out for the Reserve there are no past data for comparison. However, we did not record tiger signs in several of the Beats where tiger signs were seen in 2005 (as recorded in a questionnaire to the Beat guards; Jhala et al., 2005b) even within the Reserve, suggesting a decline in the area occupied by tigers as early as 2006 (Fig. 1).

TABle 2 Density estimates of tigers in Panna Tiger Reserve (Fig. 1) using 20 pairs of cameras with a total effort of 800 trap nights on 20 occasions during March-April 2006. Models: $M_{\mathrm{o}}$, null model (Darroch, 1958); $\mathrm{M}_{\mathrm{h}}$, heterogeneity model; IntJK, interpolated Jackknife estimator (Burnham \& Overton, 1978); $\mathrm{M}_{\mathrm{t}+1}$, number of tigers photo-captured; $\mathrm{M}_{\mathrm{t}+1} / \mathrm{N}$ estimates the capture probability over all sampling occasions; $\mathrm{N}$, population estimate.

\begin{tabular}{|c|c|c|c|c|c|}
\hline Model & $\begin{array}{l}\text { Individual } \\
\text { capture } \\
\text { probability }\end{array}$ & $\mathrm{M}_{\mathrm{t}+1}$ & $\mathrm{M}_{\mathrm{t}+1} / \mathrm{N}$ & $\mathrm{N}(\mathrm{SE})$ & $\begin{array}{l}\text { Density per } \\
100 \mathrm{~km}^{2}(\mathrm{SE})\end{array}$ \\
\hline $\mathrm{M}_{\mathrm{o}}$ & 0.11 & 7 & 1.00 & $7(1)$ & $3.8(1.7)$ \\
\hline $\mathrm{M}_{\mathrm{h}}(\mathrm{IntJK})$ & 0.09 & 7 & 0.77 & $9(2)$ & $4.9(1.5)$ \\
\hline
\end{tabular}

Our camera trap area $\left(185 \mathrm{~km}^{2}\right)$ was a subset of that sampled in $2002\left(418.14 \mathrm{~km}^{2}\right)$ by Karanth et al. (2004a) and covered all the Beats with high to medium density of tiger signs (Fig. 1). Our estimate of $4.9 \pm \mathrm{SE} 1.5$ tigers per $100 \mathrm{~km}^{2}$ is lower than that reported for $2002(6.94 \pm$ SE 3.23 tigers per $100 \mathrm{~km}^{2}$; Karanth et al., 2004a). This suggests a decline in tiger density in the core area of the Reserve, although the difference between the two estimates was not statistically significant. The sex ratio of the camera-trapped tigers was highly skewed towards adult males ( 2 males:1 female). The photo-captured tiger that could not be sexed was also most likely a male based on the size and shape of its pugmarks (Sharma et al., 2003). A similar male-biased sex ratio was also reported from Sariska Tiger Reserve prior to local extinction (Q. Qureshi, pers. obs.). Ungulate densities in Panna Tiger Reserve are comparable to those in other protected areas of India where large carnivores, including tigers, survive (Johnsingh, 1983; Varman \& Sukumar, 1995; Karanth \& Nichols, 1998).

Two of the photo-captured tigers were killed by poisoning during the latter part of 2006. Subsequently, Panna Tiger Reserve was occupied by dacoits in 2006 and antiinsurgency activities by the authorities lasted until 2008. In 2006-2007 local farmers on the periphery of the Reserve retaliated against the management for preventing them from farming illegally within the Reserve. These conflicts and hostile activities further compromised the protection of the Reserve and resulted in a further decline of the tiger population. Only a single male tiger appeared to remain in Panna Tiger Reserve by late December 2008 and he was last seen in January 2009 by Reserve staff. Subsequent visits by QQ and RG to the Reserve confirmed that after January 2009 no authenticated signs of tigers have been reported.

Madhya Pradesh Forest Department, in collaboration with the National Tiger, Authority and the Wildlife Institute of India conservation have reintroduced two female and one male tiger to Panna Tiger Reserve from neighbouring Bandhavgarh and Kanha Tiger Reserves. Three tigers from Ranthambore Tiger Reserve have been reintroduced in Sariska Tiger Reserve. The local extinction of tigers in Panna Tiger Reserve in 2009, along with local extinction of tigers in Sariska Tiger Reserve in 2004 (Check, 2006), exemplifies the vulnerability of tigers in small isolated reserves to organized commercial poaching, human-caused deaths, and hostility from disgruntled local communities residing within and around the reserves. Both Sariska (Avinandan et al., 2008) and Panna Tiger Reserves still have reasonably high prey densities. According to the predictive equations of Carbone \& Gittleman (2002) and Karanth et al. (2004b), Sariska and Panna have sufficient prey biomass to support $10-17$ tigers per $100 \mathrm{~km}^{2}$ in their core areas. Nevertheless tiger populations went extinct in both these reserves, supporting the notion that controlling human-induced mortality is of paramount importance in 
TABLE 3 The number of clusters detected, and their detection probability, mean size and encounter rate per km, of all ungulates and of sambar, chital and nilgai separately, with effective strip width of distance sampling and estimates of individual and cluster densities using Distance, along 14 transects (Fig. 1) with a total length of $126 \mathrm{~km}$. The best model selected for all prey categories was half normal cosine.

\begin{tabular}{|c|c|c|c|c|c|c|c|}
\hline Species & $\begin{array}{l}\text { Clusters } \\
\text { detected }\end{array}$ & $\begin{array}{l}\text { Detection } \\
\text { probability }\end{array}$ & $\begin{array}{l}\text { Cluster } \\
\text { size }( \pm S E)\end{array}$ & $\begin{array}{l}\text { Encounter } \\
\text { rate per km }\end{array}$ & $\mathrm{ESW}^{2}(\mathrm{~m}, \pm \mathrm{SE})$ & $\begin{array}{l}\text { Individual } \\
\text { density }( \pm \mathrm{SE}) \\
\text { per } \mathrm{km}^{2}\end{array}$ & $\begin{array}{l}\text { Cluster } \\
\text { density }( \pm S E) \\
\text { per } \mathrm{km}^{2}\end{array}$ \\
\hline Ungulates $^{1}$ & 204 & 0.20 & $2.59(0.19)$ & 1.6 & $52.3(2.6)$ & $42.44(8.4)$ & $17.08(3.12)$ \\
\hline Sambar Cervus unicolor & 52 & 0.33 & $2.48(0.27)$ & 0.413 & $45.8(6)$ & $11.89(2.95)$ & $4.79(1.07)$ \\
\hline Chital Axis axis & 45 & 0.30 & $2.54(0.35)$ & 0.6 & $36.7(4)$ & $16.31(6.36)$ & $6.3(2.3)$ \\
\hline Nilgai Boselaphus tragocamelus & 47 & 0.22 & $2.28(0.31)$ & 0.37 & $31(4.4)$ & $16.13(5.33)$ & $7.08(2.13)$ \\
\hline
\end{tabular}

${ }^{1}$ Includes chital, sambar, nilgai, wild pig, chinkara \& four-horned antelope

${ }^{2}$ ESW, effective strip width

preventing local tiger extinctions (Chapron et al., 2008). Depletion of prey (Karanth \& Stith, 1999; Karanth et al., 2004b, 2006) is, however, a threat to the long-term persistence of tiger populations.

Reintroduction to Sariska was carried out after identification of the causes of extinction, the arrest of poachers and reduction of anthropogenic pressures by relocation of villages. In comparison, reintroduction of tigers to Panna Tiger Reserve was more ad hoc. Until management approaches address the factors that resulted in local extinctions of tigers, i.e. commercial poaching and hostility from local communities, the future of reintroduced tigers is doubtful. The current national management strategy attempts to address these issues by voluntary relocation of local communities from within the core of tiger reserves to create a disturbance free area. This is intended to be achieved by offering an attractive compensation package (Wildlife Protection Act 1972, Amendment of 2006; Gopal et al., 2007). The goodwill, trust and support of communities residing within the buffer areas of tiger reserves needs to be secured by developing an equitable mechanism to share revenues from tourism in tiger reserves and through development initiatives to enhance livelihood options (Narain et al., 2005). Communities around Panna Tiger Reserve have historically been hunter-gatherers. The lure of high economic gain from commercial poaching has transformed these skilled subsistence hunters into effective poachers. Most poachers apprehended across India originate from the region around Panna Tiger Reserve (Kumar \& Wright, 1999). The relevant authorities need to combat this organized crime with modern day approaches of intelligence gathering and sharing, and law enforcement (Kumar \& Wright, 1999). A major shortfall in implementation of conservation measures has been the lack of acknowledgement by local authorities that poaching is a problem, and therefore a failure to respond while mitigation was still possible (Pabla, 2008).

Panna Tiger Reserve is a relatively small protected area in a large area of tiger habitat (Jhala et al., 2008). The home ranges of tigers that formerly lived within the Reserve included substantial areas outside it (Chundawat et al., 1999). In such a situation a strategy of protection enforced only within the core of the Reserve is unlikely to be successful. Many tiger reserves, including Panna, do not have a buffer in the form of a multiple-use area, where land uses conducive to conservation objectives are permitted with appropriate incentives, compensation and legislation (Karanth \& Gopal, 2005; Gopal et al., 2007). Without a suitable buffer and corridors to other tiger populations the persistence of small tiger populations, even under moderate poaching pressure, is unlikely (Kenney et al., 1995; Chapron et al., 2008). A landscape-level plan, addressing strategies for tiger protection, prey enhancement in the surrounding landscape and livelihood issues for local communities, is needed for long-term conservation of the tigers of Panna and other tiger reserves.

\section{Acknowledgements}

This work was part of the All India Tiger Distribution and Status Evaluation project funded by Project Tiger Directorate, Ministry of Environment and Forests, Government of India. We are grateful to P.R. Sinha, P.B. Gangopadhaya, H.S. Pabla, Shahbaz Ahmed and A.S. Nagar for facilitation and logistic support. R. Raza, V. Atkore, S. Kathyam and P. Basu are acknowledged for their help in field data collection, GIS and map preparation. A. Royle is acknowledged for assistance in modelling tiger occupancy.

\section{References}

Avinandan, D., Sankar, K. \& Qureshi, Q. (2008) Prey selection by tigers (Panthera tigris) in Sariska Tiger Reserve, Rajasthan, India. Journal of Bombay Natural History Society, 105, 247-254.

Buckland, S.T., Anderson, D.R., Burnham, K.P., Laake, J.L., Brochers, D.L. \& Thomas, L. (2001) Introduction to Distance Sampling. Oxford University Press, Oxford, UK.

Burnham, K.P. \& Overton, W.S. (1978) Estimation of the size of a closed population when capture probabilities vary among animals. Biometrika, 65, 625-633. 
Carbone, C. \& Gittleman, J.L. (2002) A common rule for the scaling of carnivore density. Science, 295, 2273-2276.

Chao, A. \& Huggins, R.M. (2005) Classical closed population capture-recapture models. In Handbook of Capture-recapture Analysis (eds S.C. Amstrup, T.L. McDonald \& B.F.J. Manly), pp. 22-35. Princeton University Press, Princeton, USA.

Champion, H.G. \& Seth, S.K. (1968) The Forest Types of India. Government of India Publications, New Delhi, India.

Chapron, G., Miquelle, D.G., Lambert, A., Goodrich, J.M., Legendre, S. \& Clobert, J. (2008) The impact on tigers of poaching versus prey depletion. Journal of Applied Ecology, 45, 1667-1674.

Check, E. (2006) The tiger's retreat. Nature, 441, 927-930.

Chundawat, R.S., Gogate, N. \& Johnsingh, A.J.T. (1999) Tigers in Panna: preliminary results from an Indian tropical dry forest. In Riding the Tiger: Tiger Conservation in Human-Dominated Landscapes (eds J. Seidensticker, S. Christie \& P. Jackson), pp. 123-129. Cambridge University Press, Cambridge, UK.

Chundawat, R.S., Habib, B., Karanth, U., Kawanishi, K., Ahmad Khan, J., Lynam, T. et al. (2008) Panthera tigris. In IUCN Red List of Threatened Species v. 2010.1. Http://www.iucnredlist.org [accessed 14 April 2010].

Chundawat, R. \& Van Gruisen, J. et al. (2008) Panna's tigers: have they gone the Sariska way? Nothing is gained by denial. Sanctuary Asia, June 2008, 44-46.

DARROCH, J.N. (1958) The multiple-recapture census I. Estimation of a closed population. Biometrika, 45, 343-359.

Dinerstein, E., Loucks, C., Wikramanayake, E., Ginsberg, J., Sanderson, E., Seidensticker, J. et al. (2007) The fate of wild tigers. Bioscience, 57, 508-514.

Gopal, R., Sinha, P.R., Mathur, V.B., Jhala, Y.V. \& Qureshi, Q. (2007) Guidelines for Preparation of Tiger Conservation Plan. The National Tiger Conservation Authority, Ministry of Environment and Forests, Government of India, New Delhi, India.

Hines, J.E. (2006) Presence v. 2.o. Http://www.mbr-pwrc.usgs.gov/ software/presence.html [accessed January 2009].

JHAla, Y.V., Gopal, R. \& Qureshi, Q. (eds) (2008) Status of Tigers, Co-predators and Prey in India. National Tiger Conservation Authority, New Delhi, and Wildlife Institute of India, Dehradun, India.

Jhala, Y.V., Qureshi, Q. \& Gopal, R. (2005a) Methodology for estimating and monitoring tiger, prey and habitat: technical note. In Joining the Dots: The Report of the Tiger Task Force (eds S. Narain, H.S. Panwar, M. Gadgil, V. Thapar \& S. Singh), pp. 193197. Project Tiger, Ministry of Environment and Forests, New Delhi, India

Jhala, Y.V., Qureshi, Q. \& Gopal, R. (2005b) Monitoring Tigers, Co-predators, Prey and their Habitat. A Field Guide. Technical publication of Project Tiger Directorate, New Delhi and Wildlife Institute of India, Dehradun, India.

JohNSINGH, A.J.T. (1983) Large mammalian prey-predator in Bandipur. Journal of Bombay Natural History Society, 80, 1-57.

Karanth, K.U., Chundawat, R.S., Nichols, J.D. \& Kumar, N.S. (2004a) Estimation of tiger densities in the tropical dry forests of Panna, Central India, using photographic capture-recapture sampling. Animal Conservation, 7, 285-290.

Karanth, K.U. \& Gopal, R. (2005) An ecology-based policy framework for human-tiger coexistence in India. In People and Wildlife: Conflict or Coexistance? (eds R. Woodroffe, S. Thirgood \& A. Robinowitz), pp. 373-387. Cambridge University Press, Cambridge, UK.

Karanth, K.U. \& Nichols, J.D. (1998) Estimating tiger densities in India from camera trap data using photographic capture and recaptures. Ecology, 79, 2852-2862.
Karanth, K.U. \& Nichols, J.D. (2002) Monitoring Tigers and their Prey: A Manual for Researchers, Managers and Conservationists in Tropical Asia. Centre for Wildlife Studies, Bangalore, India.

Karanth, K.U., Nichols, J.D., Kumar, N. \& Hines, J.E. (2006) Assessing tiger population dynamics using photographic capturerecapture sampling. Ecology, 8, 2925-2937.

Karanth, K.U., Nichols, J.D., Kumar, N., Link, W.A. \& Hines, J.E. (2004b) Tigers and their prey: predicting carnivore densities from prey abundance. Proceedings of the National Academy of Sciences of the USA, 101, 4854-4858.

Karanth, K.U., Nichols, J.D., Seidensticker, J., Dinerstein, E., Smith, J.L.D., McDougal, C. et al. (2003) Science deficiency in conservation practice: the monitoring of tiger populations in India. Animal Conservation, 6, 141-146.

Karanth, K.U. \& Stith, B.M. (1999) Prey depletion as a critical determinant of tiger population viability. In Riding the Tiger: Tiger Conservation in Human-dominated Landscapes (eds J.

Seidensticker, S. Christie \& P. Jackson), pp. 100-113. Cambridge University Press, Cambridge, UK.

Kenney, J.S., Smith, J.L.D., Starfield, A.M. \& McDougal, C.W. (1995) The long term effects of tiger poaching on population viability. Conservation Biology, 9, 1127-1133.

Kumar, A. \& Wright, B. (1999) Combating tiger poaching and illegal wildlife trade in India. In Riding the Tiger: Tiger Conservation in Human-dominated Landscapes (eds J. Seidensticker, S. Christie \& P. Jackson), pp. 243-251. Cambridge University Press, Cambridge, UK.

Linkie, M., Chapron, G., Martyr, D.J., Holden, J. \& Leader-Williams, N. (2006) Assessing the viability of tiger populations in fragmented landscapes. Journal of Applied Ecology, 43, 576-586.

MacKenzie, D.I., Nichols, J.D., Hines, J.E., Knutson, M.G. \& FrANKLIN, A.B. (2003) Estimating site occupancy, colonization and local extinction when a species is detected imperfectly. Ecology, 84, 2200-2207.

MacKenzie, D.I., Nichols, J.D., Sutton, N., Kawanishi, K. \& BAILEY, L.L. (2005) Improving inferences in population studies of rare species that are detected imperfectly. Ecology, 86, 1101-1113.

Narain, S., Panwar, H.S., Gadgil, M., Thapar, V. \& Singh, S. (2005) Joining the Dots: The Report of the Tiger Task Force. Project Tiger, Ministry of Environment and Forests, New Delhi, India.

Nichols, J.D. \& Karanth, K.U. (2002) Statistical concepts: estimating absolute densities of tigers using capture-recapture sampling. In Monitoring Tigers and their Prey: A Manual for Researchers, Managers and Conservationists in Tropical Asia (eds K.U. Karanth \& J.D. Nichols), pp. 121-137. Centre for Wildlife Studies, Bangalore, India.

PABLA, H.S. (2008) Panna's tigers: have they gone the Sariska way? Nothing is lost in Panna ... so far. Sanctuary Asia, June 2008, 44-46.

Pollock, K.H., Nichols, J.D., Brownie, C. \& Hines, J.E. (1990) Statistical inference for capture-recapture experiments. Wildlife Monographs, 107.

Pollock, K.H. \& OTis, M.C. (1983) Robust estimation of population size in closed animal populations from capture-recapture experiments. Biometrics, 39, 1035-1049.

Qureshi, Q., Gopal, R., Kathyam, S., Basu, S., Mitra, A. \& Jhala, Y.V. (2006) Evaluating Tiger Habitat at the Tehsil Level. Project Tiger Directorate, Government of India, New Delhi, and Wildlife Institute of India, Dehradun, India. 
Rexstad, E. \& Burnham, K.P. (1991) User's Guide for Interactive Program CAPTURE. Abundance Estimation of Closed Animal Populations. Colorado State University, Fort Collins, USA.

Sharma, S., Jhala, Y. \& Sawarkar, V.B. (2003) Gender discrimination of tigers by using their pugmarks. Wildlife Society Bulletin, $31,258-264$.

SinH A, A. (2007) Panna could be next Sariska, alarm bells ring over no tiger sightings. The Indian Express, New Delhi edition, 19 December 2007 [http://www.indianexpress.com/news/pannacould-be-next-sariska-alarm-bells-ring-over-no-tiger-sightings/ 252378/o, accessed 14 June 2010].

Stanley, T.R. \& Burnham, K.P. (1999) A closure test for time specific capture-recapture data. Environment \& Ecological Statistics, 6, 197-209.

Sunquist, M., Karanth, K.U. \& Sunquist, F. (1999) Ecology, behaviour and resilience of the tiger and its conservation needs. In Riding the Tiger: Tiger Conservation in Human-dominated Landscapes (eds J. Seidensticker, S. Christie \& P. Jackson), pp. 5-18. Cambridge University Press, Cambridge, UK.

VARMAN, K.S. \& SUKUMAR, R. (1995) The line transect method for estimating densities of large mammals in a tropical deciduous forest: an evaluation of models and field experiment. Journal of Biosciences, 20, 273-287.

\section{Biographical sketches}

Rajesh Gopal is an Indian Forest Service officer from Madhya Pradesh with more than 2 decades of experience managing tiger reserves. For the past 7 years he has headed the Project Tiger Directorate at the Government of India. He previously studied barasingha Cervus duvaucelii. QAmar QuReshi has a particular interest in GIS applications and landscape modelling for conservation planning. MANISH BHARDWAJ evaluated the status of tigers as part of the India Tiger Monitoring Project and is currently involved in a research project on insects in the Western Himalaya, with a special interest on the altitudinal distribution of butterfly communities. R.K. J A G ADISH S INGH also evaluated the status of tigers as part of the India Tiger Monitoring Project and is currently working as an environmental impact assessment consultant. YADVENDRADEV JHALA studies the ecology of large carnivores and has ongoing research projects on Indian wolves, Asiatic lions, striped hyenas and tigers. 